\title{
MANAGEMENT OF CHRONIC DORSAL ROOT PAIN WITH EPIDURAL STEROID
}

\author{
JAMES B. FORREST
}

POST-HERPETIC and post-traumatic neuralgias are among the most painful conditions known and continue to present a challenge in their management. The acute lesion in both conditions is relatively short-lived and is followed by a variable period of freedom from pain. Most frequently a single peripheral nerve only is involved but occasionally several adjacent nerves are affected. Pain may begin within a few months or after several years following the acute lesion and typically is intermittent, but within a short time becomes continuous and severe, having a distribution which indicates dorsal root involvement. Superimposed on this continuous pain are episodes of very intense sharp pain occurring with increasing frequency and which radiate dromally or anti-dromally within the dermatome associated with the affected nerves. Spontaneous remissions are rare. The management of these chronic spinal neuralgias has included repeated local anaesthetic nerve blocks, transcutaneous electrical stimulation, injections of ammonium sulphate around the affected nerves, injections of absolute alcohol and other sclerosing solutions intrathecally and surgical nerve section or lateral spinal rhizotomy. ${ }^{1-4}$ Only in the case of sclerosing exheresis or surgical section is pain relief assured, but at the expense of loss of somatic sensation. The results of the other forms of treatment vary widely but will only offer temporary and partial relief in the majority of cases.

Barry and Kendall ${ }^{5}$ described the use of injections of corticosteroid into the epidural space in the treatment of intractable sciatic nerve root pain due to compression by intervertebral disc protrusion. Since that time several studies ${ }^{6-14}$ have shown that steroids applied locally in the epidural space result in marked relief of pain in a variety of lumbo-sacral conditions, particularly when there is an associated inflammatory component such as arachnoiditis and, further, that the intrathecal route does not have any significant advantage over the epidural. ${ }^{14}$ This suggested

James B. Forrest, M.B., Ch.B., Ph.D., F.F.A.R.C.S., Associate Professor, Anaesthesia and Medicine, McMaster University Medical Centre, Hamilton, Ontario, Canada, L8S 4J9.

Canad. Anaesth. Soc. J., vol. 25, no. 3, May 1978 that epidural steroid might be useful in the management of other pain syndromes of cervical, thoracic and lumbar dorsal roots. Difficulties were anticipated for injections into the epidural space in the cervical and upper thoracic regions where the dose of steroid needed at each level was unknown. For this reason the long-acting steroid, methylprednisolone acetate (DepoMedrol ${ }^{\text {s) }}$ was used in a dose determined by the volume estimated to fill the lateral wing of the epidural space at each level, as either $40 \mathrm{mg}$ per $\mathrm{ml}$ or $80 \mathrm{mg}$ per $\mathrm{ml}$.

\section{Materials and MeThods}

\section{Patient population}

Twenty-eight patients, 17 women and 11 men, of a mean age of 50 years (range 22 to 73) who presented with dorsal root pain of more than six months' duration were included in this study. These comprised three groups:

Group A - Post-herpetic neuralgia (14 patients).

Group B - Post-traumatic or surgical neuralgia (10 patients).

Group C - Idiopathic neuralgia (4 patients).

Patients with dorsal root pain associated with degenerative spinal arthropathies, neoplastic disease or intervertebral disc protrusion were not included.

\section{Management plan}

All patients were seen in consultation in the Multidisciplinary Pain Clinic at McMaster University Medical Centre and a full assessment was made of their status, including their suitability for steroid therapy, routine chest X-ray, full blood count and urinalysis. Pain intensity was assessed using a visual analogue scale (VAS), consisting of a $10 \mathrm{~cm}$ line marked on the left as "no pain", and on the right as "unbearable pain". We and others $^{15}$ have found this to be a simple and reliable index of pain sensation. Further, measurement of VAS rating on repeated occasions in individual patients is highly reproducible. One week after the clinic visit, each patient was admitted to hospital on a same-day basis. Physical 
examination, repeat measurement of VAS rating and specific recording of body weight were carried out. Patients were not given any premedication. All epidural injections were done in the surgical recovery room where full resuscitation facilities were readily available. An intravenous infusion of lactated Ringer's solution was started and the patient was placed in the lateral position with the affected dermatome lowermost. A 17gauge Tuohy needle was inserted into the epidural space at the appropriate intervertebral level using a rigorous aseptic technique and angled to the affected site. Two $\mathrm{ml}$ of bupivacaine 0.5 per cent were injected for lumbar and thoracic injections while $1 \mathrm{ml}$ sufficed in cervical injections to block single dorsal roots.

For multi-level blocks the needle was removed and re-inserted for each level and similar volumes of bupivacaine were injected. Thus it was possible to identify the affected dorsal roots. In all cases these diagnostic local anaesthetic injections resulted in complete relief of pain.

One week later, and at weekly intervals thereafter, each patient was re-admitted for epidural steroid injections to a total of three injections at each of the affected dorsal roots. The total dose of methyl-prednisolone given at any one visit did not exceed $120 \mathrm{mg}$ and was given according to the following regimen: $80 \mathrm{mg}$ for a single root involvement, $60 \mathrm{mg}$ to each for two-root involvement and $40 \mathrm{mg}$ to each for three-root involvement. Ten minutes before the injection of steroid, $\mathrm{l} \mathrm{ml}$ of bupivicaine 0.5 per cent for thoracic and lumbar roots and $0.5 \mathrm{ml}$ for cervical roots was injected through the epidural needle to reduce the burning sensation associated with the steroid injection. Each patient was kept in the lateral position for 30 minutes after injection and discharged from hospital not sooner than six hours later. In each case a specific record was kept of the time for return of pain after each injection as well as the VAS rating immediately before each injection (i.e., one week after the previous injection) and at one, three, six and twelve months after the final injection.

\section{Results}

The response to epidural steroid injections for each group as measured by VAS ratings is summarized for each patient in Table I for Group A, Table II for Group B, and Table III for Group C. The overall response to each injection is shown as a mean compared to control VAS ratings for each group in Table IV.

\section{Group A-Post-herpetic neuralgia}

Nine patients in this group had a single dorsal root affected and five had two adjacent roots involved. Eleven patients had thoracic, two had lumbar, and one had cervical dorsal root pain. The mean duration of symptoms before treatment was 4.2 years (range 6 months to 10 years). The mean VAS rating before local anaesthetic diangostic block was $83.9 \pm 5.8( \pm 1 \mathrm{SD})$. One week later, but before the first steroid injection, the mean VAS was unchanged at $83.6 \pm 6.6$, but was significantly reduced before the second injection, when the mean was $60.5 \pm 12.1$. Subsequent steroid injections resulted in a further marked reduction in pain. One month after the third steroid injection (Table I) eight of the 14 patients were completely free of pain ( 57 per cent), while in the remaining six patients VAS ratings were significantly lower $(21.7 \pm 8.4)$ compared to pretreatment levels $(85.8 \pm 5.7)$. Two of these patient $s$ with residual discomfort at one month were pain-free at three months, while a further two patients continued to improve and at six months were also free of pain, giving an overall rate of 86 per cent who were free of pain at six months. Two patients had increased pain three months after the initial series of steroid injections, but following a single further injection of steroid were free of pain three and nine months later respectively. Nine patients have been followed for one year and, of these, eight were completely pain-free and include three who were still free of pain after 18 months.

\section{Group B - Post-surgical or post-tratmatic neuralgia}

This group comprised four patients with postthoracotomy neuralgia, three patients with postcholecystectomy neuralgia, and three patients with post-traumatic neuralgia. The four post* thoracotomy patients and two of the postcholecystectomy patients had single nerve root involvement while all others had two dorsal roots affected. In nine instances thoracic roots only were involved, while one also had involvement of the first lumbar root. The mean duration of symptoms before steroid injection was 3.8 years (range 2 to 8 years) with a mean VAS rating of $79.2 \pm 7.7$. This was unchanged after local anae sthetic blocks but was reduced to $59.0 \pm 16.3$ following the first steroid injection and to $36.8 \pm$ 17.3 after the second. One month after the third steroid injection 40 per cent of the patients in this group were completely free of pain. The residual pain in the remaining patients was less severe 


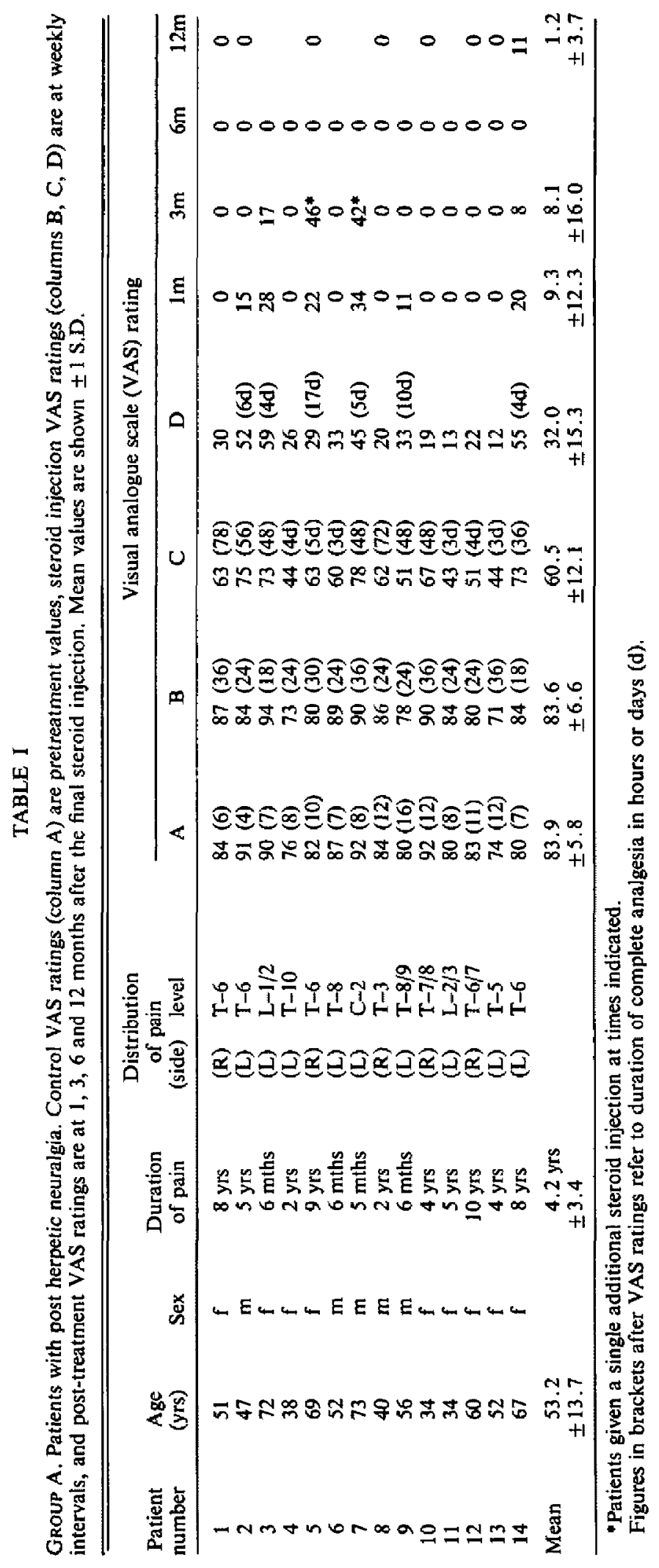




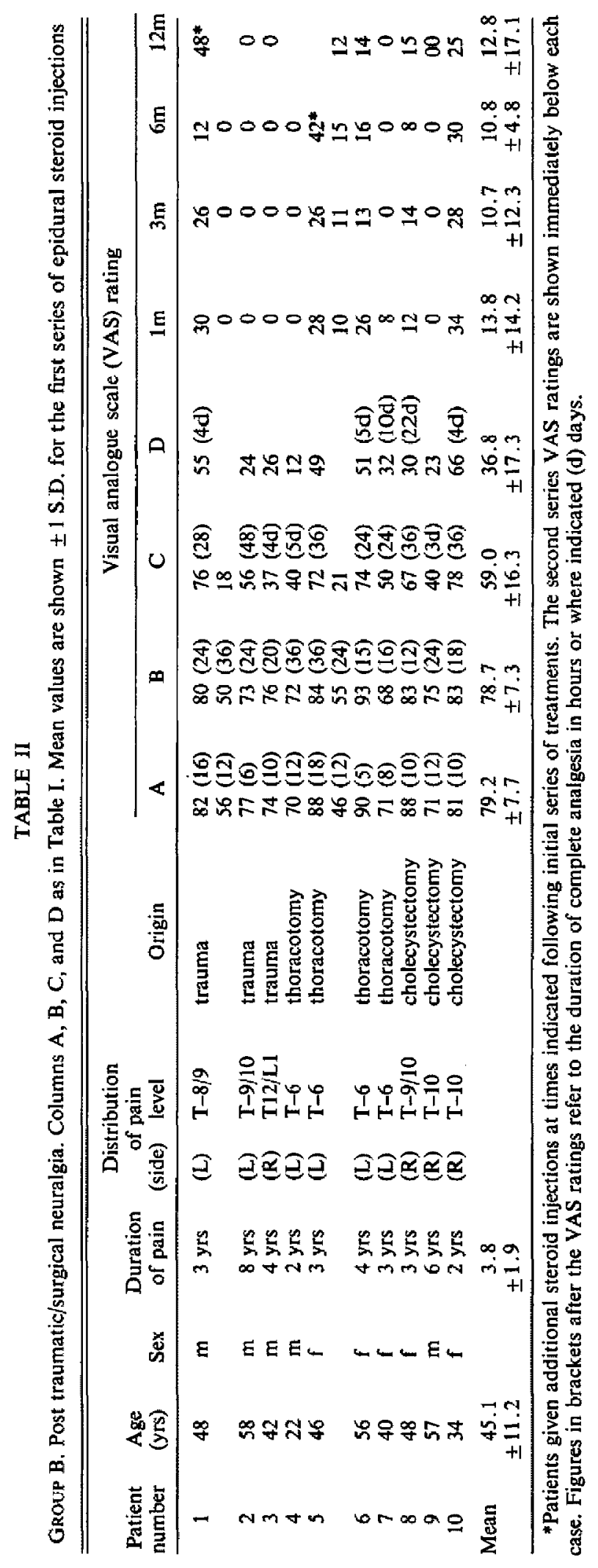




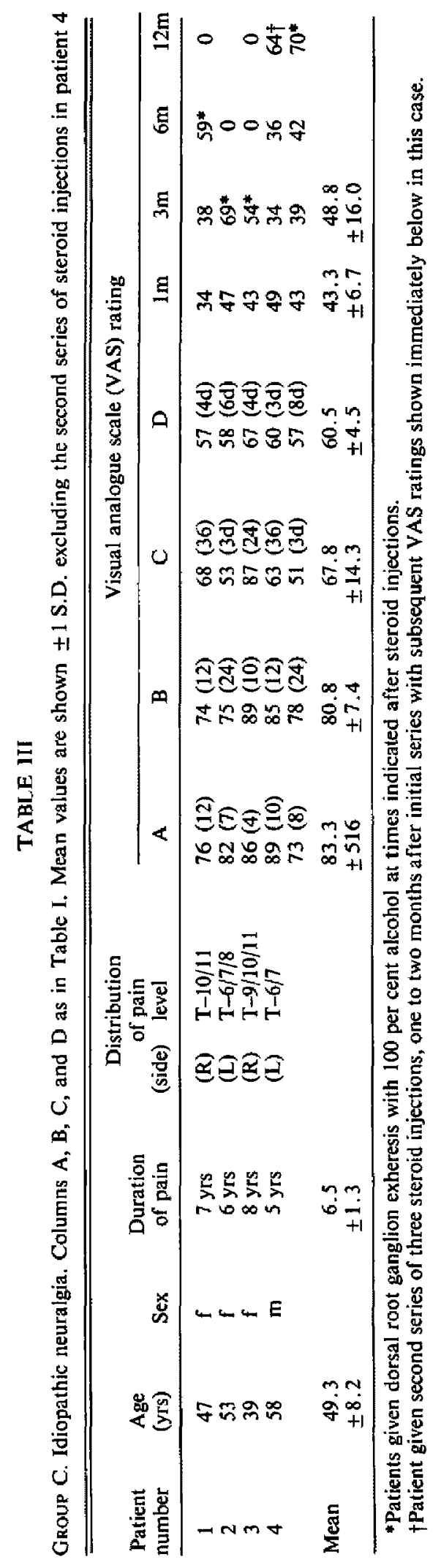


TABLE IV

Summary of the Response to Epidural Steroid InJections for EACH Group, EXPressed as a Percent Change in VaS Rating Compared to Control \pm 1 S.D.

\begin{tabular}{lccc}
\hline \hline & $\begin{array}{c}\text { Post-herpes } \\
\text { zoster }\end{array}$ & $\begin{array}{c}\text { Post-surgery } \\
\text { or trauma }\end{array}$ & Idiopathic \\
\hline $\begin{array}{l}1 \text { wk after local } \\
\text { anaesthetic block }\end{array}$ & $-0.4 \pm 4.1$ & $-0.6 \pm 4.4$ & $-1.1 \pm 6.2$ \\
$\begin{array}{l}1 \text { wk after first } \\
\text { steroid block }\end{array}$ & $-28.3 \pm 11.2$ & $-26.4 \pm 15.5$ & $-20.8 \pm 15.5$ \\
$\begin{array}{l}1 \text { wk after second } \\
\text { steroid block }\end{array}$ & $-62.3 \pm 17.1$ & $-54.4 \pm 19.5$ & $-26.2 \pm 4.7$ \\
$\begin{array}{l}1 \text { mth after third } \\
\text { steroid block }\end{array}$ & $-89.3 \pm 14.0$ & $-83.6 \pm 16.9$ & $-46.8 \pm 5.8$ \\
3 months & $-92.2 \pm 16.0$ & $-87.4 \pm 14.7$ & $-42.3 \pm 17.2$ \\
$\begin{array}{l}6 \text { months } \\
12 \text { months }\end{array}$ & $-100.0 \pm 0.0$ & $-87.4 \pm 17.2$ & $-41.5 \pm 18.6$ \\
\hline
\end{tabular}

$(23.0 \pm 10.5)$, compared to pretreatment levels $(83.3 \pm 7.0)$. Five patients $(50$ per cent) continued to have residual pain at six months and one of these required a further series of two steroid injections. One year later, this patient still had some mild discomfort. One other patient had increased pain one year after the initial treatments and was given a second series of two injections. Six months later this patient was free of pain.

\section{Group C-Idiopathic neuralgia}

All the patients in this small group had multilevel involvement, but, like the other groups, in each case only one side was affected. The duration of symptoms ranged from five to eight years. The mean VAS rating before the local anaesthetic blocks was $83.3 \pm 5.6$. As with the other groups, this was unchanged one week later before the steroid injections, when VAS rating was $80.8 \pm$ 7.4. One month after the third injection of steroid, the $\mathrm{VAS}$ rating was reduced to $43.3 \pm 6.7$. Two patients in this group had marked increase in pain after three months which required injection of 100 per cent alcohol to the affected root ganglion. One patient had return of pain at 12 months and was given a second series of three steroid injections with some improvement, but one year later required alcohol exheresis.

\section{Summary of Results}

Table IV shows the mean change in VAS ratings as a percentage of control values for each group after each injection. In the post-herpetic and traumatic groups (Groups A and B) the VAS rating was reduced to 11 per cent and 16 per cent of control values respectively, compared with a reduction to 53 per cent of control values for Group C (idiopathic neuralgia). Six months after the final steroid injection the VAS rating in Group $A$ was reduced to zero, while in Groups $B$ and $C$ VAS ratings were 12 per cent and 59 per cent of control values respectively.

\section{Complications}

The side effects from steroid administration into the epidural space were minor. In 23 cases ( 82 per cent) some weight gain occurred, the mean increase being $2.7 \pm 0.4 \mathrm{~kg}$ (range 0.7 to 6.8 kg); 16 patients ( 57 per cent) showed a slight increase in resting blood pressure (mean increase $10 / 5 \mathrm{~mm} \mathrm{Hg}$ ). No other adverse effects were noted. In virtually all cases, appetite increased and there was a general feeling of well-being even when residual pain persisted. Complications arising from the technique of epidural injection occurred in only two instances in a total of 189 injections and both cases were due to sudden movement of the patient during insertion of the needle. In one of these (patient 7 , Table I) pene. tration of the vertebral artery sheath occurred during insertion of the needle at the second cervical dorsal root ganglion. The planned steroid injection was abandoned and the patient was readmitted one week later for the procedure. In the second case (patient 3, Table I) penetration of the dura mater occurred during a lumbar injection. This patient had post-herpetic neuralgia of short duration but had also had a laminectomy done 15 years previously for lumbar disc disease. In this case, steroid was injected after withdrawal and reinsertion of the needle. This patient experienced a moderate "spinal headache" which lasted about four hours, but which resolved spontaneously with bed rest. Subsequent steroid injections in this patient were uneventful.

In eight patients ( 29 per cent) the blood pres- 
sure was reduced slightly after injection of local anaesthetic but returned quickly to normal on increasing the rate of infusion of lactated Ringer's solution. A small transient reduction in blood pressure occurred on epidural injection of steroid in seven patients ( 25 per cent). The mean reduction in blood pressure in these 15 instances was $8 / 6 \mathrm{~mm} \mathrm{Hg}$ (range up to $15 \mathrm{~mm} \mathrm{Hg}$ systolic, and 10 $\mathrm{mm} \mathrm{Hg}$ diastolic).

\section{Discussion}

Epidural steroid injections have been described in a series of patients presenting with typical posterior root pain. These have been grouped according to known aetiological factors. Improvement in symptoms was most marked in the post-herpetic group where 71 per cent were free of pain after three months, and 86 per cent after six months. Only two patients (14 per cent) in this group required a subsequent steroid injection three months after initial treatment. This compares with the post trauma and post-surgical group where 50 per cent of patients were free of pain after three months. This was unchanged after six months. Two patients ( 20 per cent) in this group required a further series of two steroid injections. The over-all rate for freedom from pain in these two groups after six months was 77 per cent and at 12 months it was 67 per cent.

In both groups, marked improvement in symptoms occurred in all cases with only one patient ( 4 per cent) having residual pain with a VAS rating greater than $\mathbf{4 0}$ after a year. The relatively poor result in the idiopathic group is difficult to explain. However, a noteworthy feature of this group was that little change occurred after a second steroid injection, where the VAS rating was only reduced by 26 per cent compared to control values. This compares with Groups A and $B$ where $V A S$ ratings were reduced by 62 per cent and 54 per cent respectively at this time. Thus after the second epidural steroid injection, one might be able to predict the ultimate outcome. On the other hand, Harley ${ }^{7}$ has suggested that, for patients with lumbo-sacral pain syndromes, there is nothing to be gained by giving more than a single epidural steroid injection. The results presented here for the post-herpetic and the post-trauma and post-surgical neuralgias clearly points to the advantage of administering serial steroid injections.

Despite the now fairly widespread use of steroids in lumbo-sacral pain syndromes, the mechanism of action remains obscure. Lysis of adhesions, reduction of inflammation of nerve root, interruption of sympathetic reflex activity, have all been suggested as possible explanations of the action of steroids. The neurophilic virus responsible for Herpes zoster quickly enters the spinal dorsal root ganglion following initial exposure and may remain there for many years in a dormant state. ${ }^{16}$ Much evidence now exists to suggest that the herpes viruses of varicella (chicken-pox) and zoster are identical, but there is no explanation for their predeliction for spinal, trigeminal and facial nerves. The virus may be activated by a number of factors, presumably also including trauma to the peripheral nerve giving rise to lesions of the posterior horn cells. The round cell infiltrate which characterizes the inflammatory process in the ganglion can give rise to either focal or diffuse degeneration. Fibrosis is a common sequel. One might expect therefore that steroids, if given in the early stage of inflammation, might result in better improvement than when fibrosis is well established. However, no relationship was found between the interval from the initial infection to the onset of pain, or with the duration of pain; nor was there any significant correlation with age of the patient, although the older patients tended to do less well. The improvement seen in the post-trauma post-surgical group might be related to the fact that the lesion of the posterior root ganglion is similar to that seen after herpes zoster infection. ${ }^{7}$

Local anaesthetic blocks have long been used in the treatment of post-herpetic neuralgias and if used in the acute phase will result in dramatic relief of symptoms. ${ }^{3}$ However, when used for post-herpetic symptoms only 40 per cent of patients will have long-tern relief. ${ }^{16}$ The results which are presented here from this relatively small series of patients with post-herpetic and traumatic neuralgias suggest that a significant improvement in symptoms occurs following the use of serial epidural steroid injections. Thus the use of sclerosing exheresis or surgical intervention would seem to be indicated only as a last resort, where steroid therapy is contraindicated and local anaesthetic blocks have failed to give relief.

\section{SUMMARY}

Twenty-eight patients presenting with typical dorsal root pain of more than six months' duration were given a series of three epidural injections of methylprednisolone acetate. The patients were grouped according to known 
aetiologic factors. Improvement in symptoms was most marked in the post-herpetic group where 86 per cent were free of pain after six months. In the post-trauma/surgical group, $50 \mathrm{per}$ cent of patients were free of pain after six months, while in the idiopathic group only minimal improvement occurred. The side-effects of steroid administration into the epidural space were in all cases minor.

\section{RÉSUMÉ}

Vingt-huit patients présentant des douleurs radiculaires typiques depuis plus de six mois, ont reçu une série de trois injections d'acétate de méthylprednisolone par voie péridurale. C'est chez le groupe de malades dont les douleurs étaient consécutives à un herpès que les résultats ont été les meilleurs: en effet, 86 pour cent des patients de ce groupe n'avaient plus de douleurs six mois après les injections. Dans les cas de névralgies post-traumatiques ou post-chirurgicales, on observait une disparition des douleurs six mois après le traitement chez 50 pour cent des patients. Enfin, on n'a observé qu'une amélioration minime dans les cas de néuralgies idiopathiques. Les effets secondaires observés à la suite des injections péridurales de stéroides ont tous èté d’ordre mineur.

\section{ACKNOWLEDGEMENTS}

The assistance of Mr. Brian Winter, Upjohn Co., Ltd., Canada in conducting a literature search, and of Miss Joyce Brandsen in preparing the manuscript is gratefully acknowledged.

\section{REFERENCES}

1. LONG, D.M. \& HAGFORS, N. Electrical stimulation in the nervous system: the current status of electrical stimulation of the nervous system for relief of pain. Pain l: 109-123 (1975).

2. MILLER, R.D. Treatment of intercostal neuralgia with $10 \%$ ammonium sulphate. Proc. Amer. Soc. Anesthesiol. Ann. Meeting, Washington, A.S.A. Inc., (abstract), pp. 171-172 (1974).

3. GoRDON, R.A. The application of nerve block in diagnosis and therapy. CMAJ 60:251-257 (1949).

4. SchurmanN, K. Fundamental principles of the surgical treatment of pain. J.P. Payne and R.A.P. Burt (Eds.), Pain: Basic principles - Pharmacology, Therapy. Churchill Livingston, London, pp. $181-193(1972)$.

5. BarRY, P.J.C. \& Kendall, P.H. Corticosteroid infiltration of the extradural space. Annals. Phys. Med. 6: 267-273 (1962).

6. Dilke, T.F., Burry, H.C. \& Grahame, R. Extradural corticosteroid injection in the management of lumbar nerve root compression. Brit. Med. J. 2: 635-637 (1973).

7. HARLEY, C. Extradural corticosteroid infiltration: a follow-up study of 50 cases. Annals. Phys. Med. 9: 22-28(1966).

8. KIM, S.I. \& SADOVE, M.S. Caudal-epidural corticosteroids in post-laminectomy syndrome: treatment for low back pain. Comp. Ther. $1: 57-60$ (1975).

9. KletschKa, H.D. \& Sheehan, L.C. Editorial: Solu-Medrol for back pain. Minnesota Med. 54 : 207 (1971),

10. Krampac, O. Long-term experiences with local administration of Depo-Medrol (methylprednisolone acetate) in the treatment of various rheumatic diseases. Reumatizam 22: 177-181 (1975).

11. Porsia, F. \& Del Re, D. A proposito di 100 casi di sindromi lombo-sciatalgiche trattate con cortisone peridurale. Minerva Med. 66: 3231-3232 (1975).

12. Sayle-Creer, W. \& Swedlow, M. Epidural injections for the relief of lumbo-sciatic pain. Acta Orthop. Belgica 35: 728-734 (1969).

13. TKaCzUK, H. Intrathecal prednisolone therapy in postoperative arachnoiditis following operation of herniated disc. Acta Orthop. Scand. 47: 388-390 (1976).

14. WINNIE, A.P. \& RAMAMURTHY, S. Steroids for discogenic pain. Proc. VI World Congress of Anaesthesiology, American Elsevier Pub. Co. Inc., N.Y., p. 139 (abstract, 1976).

15. Ohnhaus, E.E. \& ADler, R. Methodological problems in the measurement of pain: a comparison between the verbal rating scale and the visual analogue scale. Pain $1: 379-384$ (1975).

16. MiYazaki, T. \& ONDA, M. The nerve block treatment of herpes zoster. Proc. Amer. Soc. Anesthesiol. Ann. Meeting, Washington, A.S.A., pp. 173-174 (abstract) (1974). 